\title{
Acute kidney injury due to multiple wasp stings in an eight- year-old child
}

Dhakal AK ${ }^{1}$, Basnet $\mathrm{NB}^{2}$, Shrestha $\mathrm{D}^{3}$

${ }^{1}$ Ajaya Kumar Dhakal, Lecturer, Department of Paediatrics, ${ }^{2}$ Nabin Bahadur Basnet, Lecturer, Department of Nephrology, ${ }^{3}$ Devendra Shrestha, Associate Professor, Department of Paediatrics, KIST Medical College, Lalitpur,

Nepal

\section{Abstract}

Wasp stings are not uncommon in Nepal. The manifestations of stings are usually benign and localised at the site of stings. However, susceptible individuals may present with multi-systemic and potentially fatal complications. We report here a child who developed acute kidney injury, nine days after multiple wasp stings. The renal function recovered with supportive management including two sessions of haemodialysis. This case report highlights that management of wasp stings should be done in consultation with centre which has facilities for dialysis.

Keywords: Acute kidney injury; Wasp stings; Wasp toxins.

\section{INTRODUCTION}

W asp stings are not infrequent in Nepal and cases of acute kidney injury in children following wasp stings have been reported ${ }^{1}$. The manifestations range from pain, erythema and oedema at the site of sting to anaphylaxis, generalised urticaria, angioedema and dyspnoea which usually occur within 10 minutes of sting ${ }^{2}$. Intravascular haemolysis, myocardial infarction, pulmonary haemorrhage, thrombocytopenia, rhabdomyolysis and acute kidney injury are atypical multisystem reactions to stings ${ }^{3}$. Herein we report an eight-year-old boy who presented with acute kidney injury due to suspected intravascular haemolysis following multiple wasp stings. This case report highlights the diverse manifestations of wasp stings and intends to increase awareness among paediatricians.

\section{CASE REPORT}

An eight-year-old boy was referred from a primary health centre with a history of fever and vomiting for nine days

Address for correspondence:
Dr. Ajaya Kumar Dhakal
Lecturer
Department of Paediatrics
KIST Medical College, Lalitpur, Nepal
Email: ajayakdhakal@gmail.com

along with increased irritability and decreased urine output for two days following multiple wasp stings during cattle grazing in a jungle nine days ago. There was no history of seizure, dyspnoea, bleeding manifestations, oedema, rashes, muscle pain and red coloured urine. He had no previous history of wasp stings, atopic disease or bronchial asthma.

On examination the child was pale, afebrile and irritable; and there were 23 black, necrosed wasp sting scars over head, neck and upper back. Pulse rate, blood pressure, respiratory rate and oxygen saturation were $72 /$ minute, $110 / 70 \mathrm{mmHg}, 22 /$ minute, $98 \%$ in room air respectively and rest of systemic examination were within normal limits.

The investigations done one day prior to admission were haemoglobin $6.8 \mathrm{~g} / \mathrm{dl}$, total leukocyte count $11,900 / \mathrm{mm}^{3}$ (neutrophils $86 \%$, lymphocytes $14 \%$ ), platelets 365,000 / $\mathrm{mm}^{3}$, urea $136 \mathrm{mg} / \mathrm{dl}$ and creatinine $6.6 \mathrm{mg} / \mathrm{dl}$. Urine routine examination showed plenty of pus cells and trace albumin with no haematuria. Investigations at the time of admission revealed haemoglobin $6.3 \mathrm{gm} / \mathrm{dl}$, packed cell volume 19 , total leukocyte count $14,600 / \mathrm{mm}^{3}$ (neutrophil $81 \%$, monocytes $02 \%$, eosinophils $02 \%$ ), reticulocyte count $1.5 \%$, blood urea $247 \mathrm{mg} / \mathrm{dl}$, creatinine $5.5 \mathrm{mg} / \mathrm{dl}$, sodium $143 \mathrm{mmol} / \mathrm{L}$, potassium $5 \mathrm{mmol} / \mathrm{L}$, uric acid 9.6 $\mathrm{mg} / \mathrm{dl}$, calcium $6 \mathrm{mg} / \mathrm{dl}$, phosphorus $5.8 \mathrm{mg} / \mathrm{dl}$, creatinine 
phosphokinase $49 \mathrm{U} / \mathrm{L}$, lactate dehydrogenase $694 \mathrm{U} / \mathrm{L}$, aspartate transaminase $25 \mathrm{U} / \mathrm{L}$, alanine transaminase 33 $\mathrm{U} / \mathrm{L}$, alkaline phosphatase $694 \mathrm{U} / \mathrm{L}$. Bilirubin level, chest $\mathrm{x}$-ray, electrocardiogram, ultrasonography abdomen and peripheral blood smear were normal.

The child was admitted with a diagnosis of acute kidney injury following multiple wasp stings. During the stay, he received general supportive care, haemodialysis for uremic encephalopathy and blood transfusion for anaemia. However, we did not use steroid in our patient. The creatinine level declined to $3.7 \mathrm{mg} / \mathrm{dl}$ and $3.1 \mathrm{mg} / \mathrm{dl}$ after two sessions of haemodialysis done on first and second day of admission. The child was also managed with injectable Ceftriaxone as child was toxic at presentation with total leukocytes on higher side which was stopped after negative urine and blood culture reports. General condition of the child improved along with normalization of haemoglobin within 48 hours. Renal biopsy was not considered as renal functions improved. He was discharged on the tenth day of admission when creatinine level was $1.7 \mathrm{mg} / \mathrm{dl}$. The follow up renal function tests were normal.

\section{DISCUSSION}

A wasp when threatened or attacked, stings in self defence while mass envenomation occurs when their colony is disturbed ${ }^{4}$. Wasp toxins include histamines, serotonin, phospholipase, hyaluronidase and antigen 5 which cause different clinical manifestations following wasp stings ${ }^{2,5}$. Children of all age and sex are vulnerable to wasp sting ${ }^{1,6,7}$.

Anaphylaxis is a dreaded complication occurring within first few hours after the stings. It may be followed by liver injury, coagulation derangements, rhabdomyolysis or haemolysis which peak in one to three days. This may further be followed by kidney injury that peaks in four to nine days in susceptible patients ${ }^{7}$.

Kidney injury and death can occur with 20-200 wasp stings ${ }^{4}$. However a fatal case of child with multiorgan dysfunction syndrome after a single wasp sting has also been reported ${ }^{8}$. The morbidity therefore may depend not only upon number of stings but also on the strength of venom and susceptibility of children.

The incidence of acute kidney injury following wasp sting in children is not precisely known although seven out of $45(15.5 \%)$ patients had developed acute kidney injury in a retrospective study in Thailand ${ }^{6}$. Causes of acute kidney injury were rhabdomyolysis and intravascular haemolysis in this study ${ }^{6}$.

The cause of acute kidney injury after wasp stings is unclear and may be "multifactorial". Anaphylaxis associated hypotension and hypovolaemia along with other associated factors can lead to acute tubular necrosis. A study reported cases of acute kidney injury due to Hymenoptera bites and found evidence of haemolysis and/or rhabdomyolysis in all patients and concluded acute tubular necrosis due to pigment nephropathy secondary to haemoglobinuria or myoglobinuria, to be the cause of acute kidney injury ${ }^{9}$. The earlier case reports of acute kidney injury without evidence of haemolysis and rhabdomyolysis were thought to be due to direct cytotoxic effects of different constituents of venom on nephrons but renal biopsies were not done to ascertain the diagnosis ${ }^{10}$. Subsequently there were many case series of acute kidney injury without evidence of shock, haemolysis or rhabdomyolysis which were found to be due to acute interstitial nephritis on renal biopsy ${ }^{11,12}$. Similarly a combination of acute tubulointerstitial nephritis and acute tubular nephropathy has also been described causing acute kidney injury ${ }^{13}$. Recently delayed onset immune mediated interstitial nephritis following multiple wasp stings has also been described where there were minimal clinical manifestation at time of sting followed by gradual reduction in urine output after one week ${ }^{14}$.

Acute tubular necrosis following intravascular haemolysis was suspected due to anaemia, high $\mathrm{LDH}$ level, normal CPK level and no history of prior exposure to nephrotoxic drugs in our patient. However peripheral blood smear and reticulocyte count were normal which may be because these tests were done after nine days of the wasp stings. The exact cause of acute kidney injury could not be ascertained as renal biopsy was not performed. Interstitial nephritis, direct nephrons toxicity or combinations of these factors as cause of acute renal failure could not be ruled out.

Acute kidney injury secondary to Hymenoptera stings might present as oligouria, anuria, microscopic or macroscopic haematuria and hypotension ${ }^{15}$. Our patient also presented with decreased urine output and uraemia. 
Duration of hospital stay of this child was 10 days and he underwent two sessions of haemodialysis similar to previous studies where hospital stay ranged from one to 39 days and $86 \%$ of patients underwent dialysis ${ }^{15}$. This highlights that these patients should be managed in consultation with centre with facilities for peritoneal dialysis or haemodialysis.

Acute kidney injury is usually reversible with recovery varying from few days to weeks and most of the patients recover within a month's time ${ }^{1,4,12,14}$. Renal biopsy is recommended when renal function is deteriorating or not improving to detect renal lesion as that determines specific drug treatment ${ }^{13}$. Acute interstitial nephritis can

\section{REFERENCES}

1. Bhatta N, Singh R, Sharma S, Sinnha A, Raja S. Acute renal failure following multiple wasp stings. Pediatr Nephrol. 2005;20(12):1809-10. doi: 10.1007/s00467-005-2044-0. PubMed PMID: 16222551.

2. Ewan PW. Venom allergy. BMJ. 1998;316(7141):1365-8. PubMed PMID: 9563993; PubMed Central PMCID: PMC1113072.

3. Reisman RE. Unusual reactions to insect stings. Curr Opin Allergy Clin Immunol. 2005;5(4):355-8. PubMed PMID: 15985819.

4. Vetter RS, Visscher PK, Camazine S. Mass envenomations by honey bees and wasps. West J Med. 1999;170(4):223-7. PubMed PMID: 10344177; PubMed Central PMCID: PMC1305553.

5. Habermann E. Bee and wasp venoms. Science. 1972;177(4046):314-22. Epub 1972/07/28. PubMed PMID: 4113805.

6. Vachvanichsanong $P$, Dissaneewate $P$. Acute renal failure following wasp sting in children. Eur $\mathrm{J}$ Pediatr. 2009;168(8):991-4. doi: 10.1007/s00431008-0909-5. PubMed PMID: 19148679.

7. Broides A, Maimon MS, Landau D, Press J, Lifshitz M. Multiple hymenoptera stings in children: clinical and laboratory manifestations. Eur J Pediatr. 2010;169(10):1227-31. doi: 10.1007/s00431-0101209-4. PubMed PMID: 20461529.

8. Sharmila RR, Chetan G, Narayanan P, Srinivasan S. Multiple organ dysfunction syndrome following single wasp sting. Indian J Pediatr. 2007;74(12):1111-2. PubMed PMID: 18174648. be treated with steroid ${ }^{11-14}$. Steroid reduces interstitial fibrosis in acute interstitial nephritis helping early renal recovery and ultimately preventing irreversible kidney damage $^{13}$. The long term renal morbidity of wasp stings are not known precisely so prompt recognition and treatment is very important to prevent renal damage.

\section{CONCLUSION}

Wasp stings can cause acute kidney injury by different mechanisms. Early recognition of complications and prompt management with referral to centre with dialysis when indicated can help in preventing death and early recovery of renal function and long term prognosis.

9. Thiruventhiran $\mathrm{T}$, Goh $\mathrm{BL}$, Leong $\mathrm{CL}$, Cheah $\mathrm{PL}$, Looi LM, Tan SY. Acute renal failure following multiple wasp stings. Nephrol Dial Transplant. 1999;14(1):214-7. PubMed PMID: 10052513.

10. Nace L, Bauer $P$, Lelarge $P$, Bollaert $P E$, Larcan A, Lambert $\mathrm{H}$. Multiple European wasp stings and acute renal failure. Nephron. 1992;61(4):477. PubMed PMID: 1501749.

11. Zhang R, Meleg-Smith S, Batuman V. Acute tubulointerstitial nephritis after wasp stings. Am J Kidney Dis. 2001;38(6):E33. doi: 10.1053/ ajkd.2001.29289.

12. Sharma A, Wanchu A, Mahesha V, Sakhuja V, Bambery $P$, Singh $S$. Acute tubulo-interstitial nephritis leading to acute renal failure following multiple hornet stings. BMC Nephrol. 2006;7:18. doi: 10.1186/1471-2369-7-18. PubMed PMID: 17118188; PubMed Central PMCID: PMC1664556.

13. Chao Y-W, Yang A-H, Ng Y-Y, Yang W-C. Acute interstitial nephritis and pigmented tubulopathy in a patient after wasp stings. Am J Kidney Dis. 2004;43(2):e15-e9. doi: 10.1053/j. ajkd.2003.10.025.

14. Ghosh JB, Roy M, Bala AK. Delayed onset interstitial nephritis following multiple wasp stings. Indian J Nephrol. 2009;19(2):71-3. doi: 10.4103/09714065.53326. PubMed PMID: 20368928; PubMed Central PMCID: PMC2847812.

15. Mejia Velez G. [Acute renal failure due to multiple stings by Africanized bees. Report on 43 cases]. Nefrologia. 2010;30(5):531-8. doi: 10.3265/ Nefrologia.pre2010.May.10269. PubMed PMID: 20613852. 